\title{
Beliefs of Life Cycle in the Cultural Life of Ethnic Minorities in Northwestern Vietnam in Current Context
}

\author{
Le Van Loi ${ }^{1} \&$ Hoang Thi Lan ${ }^{2}$ \\ ${ }^{1}$ Department of Scientific Management, Ho Chi Minh National Academy of Politics, Vietnam \\ ${ }^{2}$ Institute of Religion and Traditional Beliefs, Ho Chi Minh National Academy of Politics, Vietnam \\ Correspondence: Le Van Loi, Department of Scientific Management, Ho Chi Minh National Academy of Politics, \\ Ha Noi, Vietnam. Tel: 84-912-634-786. E-mail: Levanloinpa@yahoo.com
}

\author{
Received: April 13, $2019 \quad$ Accepted: April 30, $2019 \quad$ Online Published: June 12, 2019 \\ doi:10.5539/hes.v9n3p22 URL: https://doi.org/10.5539/hes.v9n3p22
}

\begin{abstract}
Beliefs of Life cycle (or life cycle - related beliefs) of ethnic minorities in the Northwestern region of Vietnam are the beliefs related to the lives of people in this region from birth to death which carried out through basic rituals such as: the rituals in childbirth, marriage, funeral and rituals of treatment, etc. The beliefs of life cycle plays an important role in the cultural life of ethnic minorities: helping people have psychological balance before the steps of birth - old age - sickness - death in the human life; a place that aspires for a peaceful, happy life and maintains the emotional attachment between generations and with the community; a place that preserves many cultural values with humanity, morality, ethic values and unique artistic values, contributing to the cultural nuances of ethnic groups in the Northwestern region. In the current context, the life cycle beliefs of ethnic minorities in the Northwestern region are having a strong recovery, creating conditions for good cultural values of this kind of beliefs to promote the role in cultural life of ethnic minorities. However, the tendency of recovery both prolix and expensive rituals and miscellaneous cultural features, unsound customs as well as outdated habits are posing many challenges, requiring effective solutions to preserve and promote the good cultural values in this kind of beliefs of ethnic minorities in the Northwestern mountainous region of Vietnam in the current context.
\end{abstract}

Keywords: beliefs of life cycle, change of the life cycle beliefs, Northwestern mountainous region of Vietnam

\section{Introduction}

The Northwestern region of Vietnam covers an area of about 50,810 km2, including Son La, Dien Bien, Lai Chau, Lao Cai, Yen Bai and Hoa Binh provinces. This is an important strategic location for security and defense, and is the gateway to the northwest of Vietnam. The Northwestern region is a region with a diverse population, including many different ethnic groups (more than 30 ethnic groups) such as Kinh, Thai, Muong, Hmong, Dao, Tay, K'Mu, Giay, Ha Nhi, Lao, Lu, Cong, Si La, San Diu, etc. In particular, ethnic minority people make up more than $60 \%$ of the population living in this region. Ethnic minorities with relatively large populations include Thai, Muong and Hmong. In recent years, many traditional cultural beliefs of ethnic minority people lost in oblivion over time have been gradually restored, contributing to further enhance the cultural identity of Vietnam. Ethnic minorities in the Northwestern mountainous region of Vietnam have a rich and diverse system of life cycle rituals. Life cycle rituals express the beliefs related to each individual. Each ethnic group has certain taboos and rituals around important milestones in the life cycle of a person from birth to death. The richness, diversity of expression and unique values imbued with the ethnic cultural identity of the life cycle beliefs have attracted many researchers to understand this phenomenon.

Nguyen Dang Duy (2001) in Forms of Religious beliefs in Vietnam has analyzed the origin and features of some traditional beliefs of Vietnamese people. In particular, the author has also introduced the life cycle beliefs of ethnic minorities such as Muong, Thai, Tay, Nung, Hmong, Dao people and affirmed that this is a kind of beliefs associated with the mountain and forest environment in human conditions and have not explained the phenomenon of crops, health, etc. In Beliefs and Religious culture in Vietnam, the author Ngo Duc Thinh (2001) presents the traditional beliefs of ethnic groups such as worshiping ancestors, life cycle beliefs, mother goddesses, Saint Tran Hung Dao, etc. These beliefs are not only popular in Vietnamese people but also preserved in some other ethnic groups such as Muong, Thai, Dao, Tay, Nung, etc. Le Trung Vu (1999) in Rituals of life cycle discusses the rituals in childbirth, maturity, marriage and funeral of Vietnamese people, in paticular, the 
rituals of funeral and ancestor worship. Pham Minh Thao (2004) in Funeral customs has presented the funeral customs of some countries in the world and Vietnam. In particular, the author analyzes the specific features of the funeral rituals in the lives of people in some ethnic groups in Vietnam. Thereby, the author has recreated a part of the religious culture of some ethnic groups in Vietnam and the world. Nguyen Tho Khang (2013) in Cultural features and values of folk beliefs in Vietnam has analyzed Vietnamese folk beliefs "formed and developed in the forms of major folk beliefs such as: worship of ancestors (ancestral worship), worship of gods (god worship), professional beliefs, beliefs and rituals of individual (life cycle), etc."

Tran Van Binh (2004) in Northwestern ethnic culture - actual situation and issues has focused on clarifying the cultural features of ethnic groups such as Thai, Hmong, Muong in the Northwestern region. In particular, the author has analyzed the actual situation of preservation and promotion of cultural and belief values of ethnic minorities in the Northwestern region. In Beliefs of ethnic minorities in the northern mountainous region of Vietnam, Hoang Thi Lan (2016) has commented on the spiritual life and beliefs of ethnic minorities in this region which is quite rich and diverse. The author analyzes the actual situation of beliefs of people in this region through some kinds: ancestor worship, beliefs related to the community, beliefs related to nature, beliefs related to production and beliefs related to the life cycle".

Many in-depth studies of traditional beliefs of each ethnic minority community living in the provinces of the Northwestern region of Vietnam show the common and unique cultural identities of each ethnic minority community here: In Spiritual culture of the Hmong in traditional and modern Vietnam Vuong Duy Quang (2005) has clarified the economic and socio-cultural features of the Hmong people. The author has analyzed the actual situation of some traditional beliefs of Hmong people and mentioned the rituals of births, marriages and funerals of Hmong people in Vietnam in the current context. In Thai people in Northwestern region of Vietnam, the author has clarified the features of ethnicity, economy, society, religion, traditional beliefs, culture and arts of Thai people. In particular, the author introduces the relevant rituals in the life cycle belief of Thai people (Cam Trong, 1978). In Culture of ethnic groups in the Northwestern region of Vietnam, Lam Ba Nam (2005) has mentioned the cultural features of ethnic groups in the Northwestern region, show the differences in the culture of some ethnic groups and have in-depth analysis of cultural features, the role of traditional beliefs (ancestor worship, lifelong beliefs, etc.) in the lives of ethnic minorities in northwestern region of Vietnam. Nguyen Thi Thanh Nga (2015) in Some basic issues on ethnic areas of ethnic groups in the Northwestern Border in Vietnam has mentioned features of material and spiritual culture of ethnic minorities in Northwestern region of Vietnam. In particular, the author emphasizes the cultural and spiritual features of some ethnic minority communities in this region and affirms the kinds of beliefs of the people here associated with polytheistic beliefs and conceptions of the universe around people created by many levels of the world.

In addition, many articles and studies in different aspects of lifecycle rituals in the lives of ethnic minorities in the Northwestern region of Vietnam such as: Something on religion of Thai people in Northwestern region of Vietnam (Hoang Tuan Cu, 2005), Culture of ethnic minorities in Vietnam (Ngo Van Le, Nguyen Van Tiep, Nguyen Van Dieu, 1998), Traditions of ethnic minorities in Vietnam Vu (Ngoc Khanh,2002), Traditional festivals and folk beliefs of Vietnamese ethnic group (northern provinces) (Hoang Luong, 2007), Hmong culture (Tran Huu Son,1996), Beliefs of Hmong people in Lao Cai in current context (Mai Trung Sam, 2008), Beliefs of Thai people in Son La in current context Cam Vi Hoa, 2009), Beliefs of Muong people in Hoa Binh (Nguyen Thi Kim Hoa, 2012), Traditional cultural values of the Thai ethnics in northwest of Vietnam for developing community-based tourism (Dang Thi Nhuan, Duong Quynh Phuong, Pham Thanh Tam, 2014), Ethnic Minorities in Vietnam (Dang Nghiem Van, Chu Thai Son, Luu Hung, 2014), ect..

Studying on the lifecycle beliefs of ethnic minorities in the Northwestern region of Vietnam, the above authors have mentioned many different aspects of the beliefs of the life cycle of ethnic minorities such as: features, forms of existence and cultural beauties of each kind of religious ritual. At the same time, the authors also analyze the actual situation, point out the advantages and outdated unsound customs of some rituals in the life cycle belief in childbirth, marriage and funerals of ethnic minorities in this region. The authors believe that with the process of cultural exchange and integration, a number of the rituals bearing the traditional cultural features of ethnic minorities in this region should be concerned with preservation, restoration, conservation to promote the traditional cultural values and also gradually eliminate outdated customs. At the same time, internal force and resistance to ethnic minority culture are enhanced, contributing to building an advanced Vietnamese culture imbued with national identity, which is a necessary task at present. This article focuses on the rituals of the life cycle beliefs, the role and change of the life cycle beliefs in the cultural life of the three most populous ethnic minorities in the Northwestern region: Thai, Muong and Hmong, and thence, providing some recommendations for solutions to promote the good cultural values in the life cycle beliefs of ethnic minorities in general in the 
Northwestern region of Vietnam at present.

\section{Contents of Study}

The life cycle beliefs is related to each individual, from birth to death. The life cycle beliefs is the belief of the community for an individual, also the beliefs for the whole society and the whole natural world surrounds people. In other words, the lifelong beliefs is a concept referring to human life from birth to death implemented through the basic rituals such as rituals in childbirth, in marriage, funeral and in treatment, etc.

\subsection{Rituals in Life Cycle Beliefs of Ethnic Minorities in Northwestern Region of Vietnam}

\subsubsection{Rituals in Childbirth}

Currently, the ethnic minorities of Thai, Muong, and Hmong in Northwestern region of Vietnam still perform many rituals related to the childbirth. Women of Thai, Muong and Hmong ethnic groups must abstain from food to daily life when giving birth to their babies.

Muong women who are pregnant must diet some foods such as: abstaining from eating fruits with two or three fruits conjoined; abstaining from eating snails because they are afraid that the baby will have much saliva; abstaining from drinking water in a big-size bamboo tube which has battered head because they are afraid that the baby will have cleft lip; abstaining from grilled fish and fish soup, because they are afraid that a placenta will be difficult to peel off when giving birth to a baby; abstaining from walking on the bark used to make coffin; abstaining from sitting on the stairs; abstaining from stepping through the rope of buffalo because they are afraid of "buffalo pregnancy" (pregnancy longer than usual); if going through the door of communal house and cemetery, it is necessary to take along the leaves into your body to eliminate ghost; abstaining from participating in festivals and rituals of villages and hamlets because people believe that the body is not clean; every morning, it is necessary to get up early and open all the doors in the house so that it is easy to give birth; in the harvest season, it is not possible to wade into the field first, etc.

Women have to give birth to their children at their husband's house. If they give birth in their mother's house, they have to give birth under the house on stilts, according to the conception of the people, if having the blood of another family falling in their house, they will face a lot of risks. If the woman is difficult to give birth, the magician will be invited to the ceremony. The placenta of the pregnant woman is put in a big-size bamboo tube to hang on a tree branch in the forest in a deserted place, without people, not letting anyone see. When the umbilical cord of the child falls, it is put on the thatched roof, right next to the staircase up and down of the house on stilts. After the birth, the woman is lying next to the cooking fire for a month if the child is the first child and from 15 days to 20 days if the child is the second and third child. Abstaining from strangers visiting women at birth. During the abstinence of pregnant women is bamboo-tube rice with grilled salt.

A month-old child is entitled to "end-abstinence" ceremony to thank the kitchen king and the midwives (when the boy was born 7 days and the girl was 9 days). When the child is a month old, the family will celebrate the village celebration (grandchild celebration) or also known as the full month ceremony. When the child often cries, is sick, there will have exorcism rituals performed by the family or the shaman. When leaving the child out of their homes, to avoid ghost teasing illnesses and sickness, Muong people often use charcoal to draw a smudge on the child's forehead with the implication of marking for the midwife to not lose her way but always beside the child and protect the child. If coming back home, the child is anorexic, the family will make a soul evocation ceremony. Children infertile families often have an altar for worshipping midwife placed in their garden. Every month, we will worship the midwife on the $15^{\text {th }}$ and the $30^{\text {th }}$ day of the lunar calendar. When the child was 12 years old, the family will celebrate a thanksgiving for the midwife and remove the altar.

Like Muong people, Thai women often have to abstain from many things during pregnancy and childbirth, avoid work at the end of pregnancy. After giving birth, within the first five days, the pregnant women will have to eat bamboo-tube rice in a bamboo tube. The bamboo tubes will be hung up after eating, when the child loses the umbilical cord, the umbilical cord is put into a bamboo tube, buried under the floor or around the garden but avoided being buried under the floor where the ghost of family is worshipped. During the first ten days of giving birth, the pregnant women abstain from strangers coming to the house. After giving birth, the pregnant woman must be lying next to the cooking fire for 10 days. After 10 days (also called end - abstinence), the family will make a ritual of worshipping the cooking fire ghost for the mother and child to return to the sleeping room everyday.

When the child is 2 months to 3 months, the naming ceremony will be made (called ook kho). On the occasion of worshiping the ghost of the family in the year (usually conducted on the second day of the Lunar New Year), the family makes a soulful container for the child and celebrates to inform the ghost of the family and ancestors (a 
soulful container is a knitting tube including one bag small cloth, there will have a piece of paper with the name, date of birth of the child and some coins in the cloth bag). After the ceremony, the soulful container is mounted under the roof (the child is male, it will be hung in the place of worshipping the ghost of the family, the child is female, it will be hung in the room next to the mother's room). Every few years, the soulful container will be replaced by new ones. When the daughter gets marriage, the soulful container will be removed. For children who are sick, difficult to raise, the soulful container will be sent to the shaman 's house. When the child goes away, the family often draws a smudge on the child's face and brings a knife to avoid the devil and ghost on the way to not dare to come near and recognize or hurt the child.

At birth date of Hmong women, if it is difficult to give birth, they must make a ceremony to wish the mother and the child in good condition, called a ceremony of đề ca sủa (offering the ghosts eating the children) and make the ceremony to apologize to parents-in-law and aunt due to the perception that women are difficult to give birth because of poor treatment to these people.

When the child is male, the placenta will be buried at the column foot of the main house with the notion that the son will later be the breadwinner. If the child is a female, the placenta will be buried under the bed with the notion that the daughter will be a good mother, a good housewife.

The child was 3 days old, the family celebrated the soul evocation ceremony (híp pli), when the child was one year old, the Hmong will make a happy birthday celebration for the child. If the child is often ill, difficult to raise, the Hmong perform the ceremony to receive a foster father for the child. In some areas, when children are often ill, the family must invite a shaman to offer to relieve the bad luck. If all these procedures have been done but the child is still sick, the Mong people make ceremony of wearing a soul bangle for the child.

\subsubsection{Rituals in Marriage}

Currently, Thai, Muong, and Hmong ethnic people have very elaborate rituals while holding a wedding ceremony. A marriage of the boys and girls of the Thai, Muong and Hmong ethnic groups is often conducted the procedures such as marriage proposal, engagement, and wedding ceremonies. However, the way to conduct rituals and offerings for each type of ceremony is different in different ethnic groups.

- Proposal ceremony: The proposal ceremony is a ritual to formalize the marriage of two families. This is the first ritual so that the families of the boy's family and girl's family meet and exchange and explore each other's thoughts, so the offerings of this ritual are usually quite simple. For Thai people, when the boy and girl have consented to each other firstly, the boy's family must send a person to girl's house to talk and explore if the girl's family agrees. After understanding the family situation of the girl, if there is no obstacle, the boy's family will proceed proposal ceremony (pay chóm). The offerings of the Thai people in the localities are different but often include a pair of live chickens (a rooster and a hen), 4 bottles of wine (double and even enough) with cakes, candies, fruits.

For Muong people, in the ritual of proposal ceremony (express a wish), there is no absence of the presence of matchmaker. The matchmaker must be a prestigious person, has a happy family, a large number of children, many grandchildren, is talented in speaking skillfully. The matchmaker will act on behalf of the boy's family to the girl's house, officially speak about the couple's marriage to the family. The two families will discuss and agree on the date of express a wish (sending word).

For the Hmong people, when the couple likes each other, or in the special case, the boy falls in love with the girl, the boy will ask some friends to "catch the wife" with him. When being taken back to the boy's house, the girl will be left alone in a room for three days. The boy's mother or sister will be the ones who persuade the girl to become the bride. After three days, if the girl agrees to wear a boy's family dress, she agrees to marry the boy. The family of the boy will ask the matchmaker to come to the girl's house to talk about marriage. The girl will be done soul ceremony and the ghost worship of family. If the girl refuses to wear a dress, she does not agree, the boy will have to take the girl back to her parents with some offerings. At present, Hmong couples love each other, when both families have agreed, the boy must also go and catch the girl but the the ritual of catching wife is only symbolic.

Similar to Muong people, the matchmaker is an important person in the wedding rituals of the Hmong people. The matchmaker selected by the boy's family must be knowledgeable about the customs of the ethnic group, know many folk songs, capable of improvising and speaking to persuade the girl's family. If both families agree, the matchmakers of the boy's family and girl's family will talk on behalf of the two families to discuss the offerings, the dates and the time of the engagement ceremony and wedding ceremony.

- Engagement ceremony: in the sense of the official announcement of the marriage promise of two families and 
two lineages. This is a ceremony marking an important step in the marriage relationship of a couple. Thence, the couple is officially recognized by their relatives as unmarried couple. In different ethnic groups, the way of organizing and offering for engagement ritual is also different.

For Thai people, the engagement ceremony (pay tam, pan khảu vay) is traditionally used to have wine, rooster, but at present, it is usually pork, rice, wine. During the engagement ceremony, the two families will discuss and make specific requests for wedding ceremony, the time when the boys must live with wife's family, etc. Previously, the Thai boys had to live with wife's family in the bride's house for 3 years, take care of everything in her family (to repay the nurture of her parents), then if the bride's family agree, they will officially get marry. In the current context, most of the customs has been simplified by converting into an amount of exacting wedding-presents (only symbolic) for the bride's family.

The ceremony of the Muong people is organized twice: the first time (called nòm gà), the offerings consist of chicken, fish, Chung cake, sticky rice, areca, betel and wine; the second time (called nòm lơn), the offerings include pig, chicken, wine, sticky rice or Chung cake, areca, betel, in addition to silver rings, a few small and square cloth and a large cloth used to make blankets to give to the grandchildren when the daughter gives birth to her first child.

The offerings for the Hmong engagement ceremony include wine, pork, chicken and rice. The two matchmakers carefully selected by the family of the boys will be with his father or his uncle to bring the offerings to the girl's house, the two families will eat and discuss the wedding ceremony together and choose the day wedding ceremony.

- Wedding ceremony: The wedding ceremony is also known as the bride procession with the meaning of proclaiming the couple's marriage. The wedding ceremony is often considered the most important ritual in most ethnic groups and is often performed with various rituals and taboos.

Thai people often choose a good day to celebrate their wedding. Usually, the bride's family celebrates a party at noon before the groom's family one day. On the day of the celebration of the bride's family, from the early morning, the groom's family sent a delegation led by $P o$ su to take the groom to the girl's house, bring with the offerings (agreed by two families on the engagement ceremony) to celebrate the bride procession (Offerings of bride procession usually include chickens, betel, shells, silver rings and cash - this is the conversion amount symbolizing for the time of living in his wife's house), etc. The representative will represent the groom's family to hand over the offerings to the bride's family. The bride's family appoints a representative (pò lăm) to receive the offerings and notice the ancestors on daughter's marriage and ask the ancestors to protect and support the daughter. In Black Thai people, before the the bride procession, there is also a ceremony of chignon for the bride (tăng cẩu). This is a sign to affirm that the daughter has got a husband. When the bride comes to her husband's house, the young couple will make a ceremony to pray for their ancestors, ask their daughters-in-law to enter the soul and family name of the husband's family and give the daughter-in-law to the family's ghost, ask for their ancestors to protect.

The wedding of Muong people usually takes place in three days. On the first day of the ceremony, the groom's family brings the offerings to the bride's house. The second day, the banquet is set up to treat guests. The third day is the day of the bride procession. Depending on the distance between the two families, the time for the bride procession is chosen so that when the bride comes to her husband's house, it is just dusk (this is the best time of the day according to the concept of Muong people).

According to the custom of Muong people, the delegation of the bride procession has go on the same road when going and returning, no one is left midway, if having fork, it is necessary to put two betel and areca on the edge of the road. The bride, when leaving the house, has to hold a small horn-edged knife, a blade with a ginger to eliminate the ghost, on the road to the husband's house, the bride should not turn to look behind her to be afraid of being unhappy later. Arriving at the foot of the stairs, the members have to wash their feet and then go up to the house. Particularly, the bride and bridesmaids must not step on the first step but must step through the bundle of wood then step on the following steps. When entering the house, the bride must kneel and bow to the kitchen king so that later she will be blessed when she gives birth, then bow to the ancestors and the upper ranks of the lineage. After that, the groom and the bride attend the red thread ceremony to be wed by matchmaker for the couple to have sons, daughters, happy families and fortune.

The wedding ceremony of the Hmong people is usually held in the winter, the wedding season abstains from thunder. The groom's house must bring two roosters, two hens to the girl's house (a pair of roosters - the hens will be used to worship the ancestors; the other pair will be used for remetting); the curling knife is used to worship the god of knife. According to the custom of the Hmong people, when the delegation of the bride 
procession to the bride's house, the number of the groom's family members must be odd, but when the delegation of the bride procession to the groom's house, the number of people in the delegation must be even. On the way, the delegation will rest, eat and drink. Before eating bố dẫn, groom's family and the prestious members of bride's family have to throw rice and meat around to invite the forest ghosts and wandering ghosts to eat so that they do not follow the bride. The delegation of the bride procession to come home, the groom has to go back quickly to light the lamp, the bride and welcomed person hve to stop in front of the door for the bride to make the the soul ceremony to enter the husband's house, etc.

\subsubsection{Rituals in Treatment}

The Thai, Muong, and Hmong ethnic minorities all conceive that the human consist of two parts of the body and the soul. When the body is sick, the soul leaves the body somewhere far away. Therefore, when having sickness, all three ethnic groups have rituals to pray for souls and peace.

Thai people have 4 ways to call the souls: The first is to call missing souls (hiếc khuôn, văn on) when people are naturally startled and fear, which makes the souls leave their bodies without knowing the way back; the second is to find the missing souls (xọc khuôn, văn). This ritual must be performed by a professional shaman (mo mọt, mo $m o ̂ n$ ); the third is to indulge the missing souls (öi khuôn, văn). This ritual is performed when the soul of a sick person is lost in a place where the sick person is too happy, the ghost is very attentive, so the soul of the sick person does not want to return; the forth is to call the souls to the elderly (hiếc khuôn, văn chàu). In addition, in the concept of the Thai people, there are many types of ghosts that can cause illness for the human, when the human suffer from certain type of ghost, they also need to make the rituals of exorcism.

According to the concept of Muong people, people are born with souls and envelopes. Therefore, after the child is born a week, people hold an envelopes ceremony for the child called a ceremony of na mu (thá $m u$ ). When facing sickness, Muong people make the envelopes ceremony a ritual (called woái thoắn) to cleanse sickness and pray healthy.

In the opinion of the Hmong people, the sickness is due to absenteeism or being caught by some type of ghost, or may even be due to offending their ancestors. Therefore, when there is a sick person in the house, the homeowner will also invite the shaman to come and find the reason. The shaman will incense to tell the ancestors of the sick family, will say the cause of the sickness and make the ceremony of chasing ghosts or the apology ceremony for the sick person.

\subsubsection{Rituals of Funeral}

According to the concept of the people here, when people die, it is not the end and that person's soul will continue to live a life in another world. Therefore, funerals of the Thai, Muong and Hmong ethnic groups are one of the rituals of nature of religion and belief. The funeral ritual of the Thai, Muong and Hmong ethnic groups has an important role in the cultural life of and is a unique cultural phenomenon with many different rituals.

Thai people conceive that when a person dies, the soul will turn into a ghost (phi), reside in 3 places: phi huon (ghost of family), phi pá heo (ghost in a grave, in a cemetery outside the ghost forest) and phi đắm mường pha, muòng Then (ancestral ghost of family in heaven). These ghosts are all good spirits, blessing for those who live and their families. However, if they are not worshiped, they will "ask for food" and cause trouble for the homeowner. Therefore, when there is person who dies, people have to make the funeral to bring the souls of the dead, worship in a customary manner.

Thai people do not abstain from taking the coffin of the dead to the normal door and stairway, but have to break the walls, make the new stairs to bring the coffin to the yard. When the delegation of the funeral on the road, the daughters and daughters-in-law must kneel down, face to the grave so that the people carrying the coffin will pass over their head twice.

For Muong people, the death is not the end. When people die, the soul continues to live a life in another world. Therefore, the funeral is one of the rituals of religious and belief features of Muong people. For young and unfortunate deaths, the funerals are usually organized simply, for the ordinary death, the funerals are organized according to very elaborate rituals. The funeral of Muong people is indispensable for mo nights. These are rituals for the dead to break with the world of the living and join in the world of the dead.

The Hmong funeral is a unique cultural phenomenon with many different ceremonies. Hmong people conceive that the world consists of 3 levels: the heaven is ancestral world; the middle is the human world and the underground level is hell, hades. According to the Hmong conception, the human have 3 souls. When they die, 3 souls are left from the body and go to 3 different places. The original soul goes to the ancestral world and lives with the ancestors' original soul. But the original soul is often in close contact with their children and 
grandchildren, which can bless or harass their children. Therefore, children and grandchildren must make offerings to this soul. The second soul will fly to the sky to ask why people must die, then live in the middle of the world of heaven. The third soul will be reincarnated to live on earth. If people live many good things when they live, they will be reincarnated as the human. Conversely, when living, people do many evil things, the souls will be reincarnated as animals such as buffaloes, cows, dogs and horses to serve the human. After paying off the sins, this soul will be reincarnated into a human life. The funeral ritual of the Hmong is closely related to the conception of the 3-level world, 3 souls of the human with a variety of rituals.

If the funeral of Thai and Muong people cannot miss the mo nights to give way to the dead, then the funerals of the Hmong people cannot lack the homily of the road (khúa kê) so that the dead souls greet the ghosts of family and bring the souls of the dead to their ancestors.

By this study, it can be seen that the life cycle belief of the three ethnic groups of Thai, Muong, Hmong as well as other ethnic minorities have the common feature that there is a ritual system associated with each life of people, from birth, growing up, growing old and dying - move to another world and still have a close relationship with those who live (in the form of the power of the soul as is the case of the Thai , Muong people or having a connection with the soul, and reincarnating as a living person as is the case of the Hmong people. However, each ethnic group has its own system of religious beliefs and rituals, expressing unique feelings and philosophies of the cosmic and humanistic universe, bearing the ethnic cultural identity. This makes the abundance, diversity and unique features of the belief of life cycle of the ethnic minorities in this region.

\subsection{The Role of Life-cycle Beliefs in the Cultural Life of Ethnic Minorities in the Northwest region of Vietnam}

For ethnic minorities in the Northwest, the life-cycle beliefs system plays a very important role in the social life. Life-cycle beliefs contain several human values, moral values, ethical values and unique artistic values, contributing to the creation of ethnic cultural identity. As a component of the ethnic cultural identity, through the life-cycle belief system, we can see the world view, the view of human life, the customs, the soul and the sentiment of ethnic minorities. The above values are expressed mostly in wedding ceremonies and funeral rituals.

The wedding ceremonies of ethnic minorities contain several unique ethnic cultural values. Marriage is an occasion for relatives to meet, encourage and share experiences with each other while funeral rituals is an occasion for people to express clearly their respect for parents and the ancestors. From birth to adulthood and marriage, the older people takes care of the younger ones and at the end of the life, the younger ones will take care of the older people. It is a responsibility, a duty and at the same time it represents human values, moral values and ethics in interpersonal relationships.Through funeral rituals, people of ethnic minorities can learn about the historical formation and development of their people and explain the eternal question of any ethnic community, that is where people go when they die. It can be said that the life-cycle belief system of ethnic minorities has partly depicted the world view and the view of human life of the ethnic groups.

The Thai, Muong and Hmong ethnic groups share the same beliefs that death is not the end and the ancestral spirits still support their children, so the children and grandchildren must show their filial piety by taking care for their parents and grandparents. Therefore, the funeral rituals of the three ethnic groups take place very formally and clearly showed sociality and community at a large scale. Every time a family holds funeral rituals, relatives of the family must support by contributing money and wealth and they must participate in it. There is also a great participation of people outside the family in and out of the village. The notion: "The neighbors' businesses are my businesses, my family's businesses are the neighbors' businesses" has become a traditional custom now and then that every member of the ethnic community must voluntarily follow all the time.

For generations, life-cycle beliefs not only partially meet the needs for awareness and for spiritual and cultural activities, but also play an important part in strengthening and building community relations in the social life of ethnic minority people. Besides, the beliefs of the life-cycle of the ethnic people also contain lots of unique artistic values. The events such as "cuoc mo", singing and so on are a rich and diverse treasure of folk poetry. Several cultural values of ethnic groups such as the "Am et", "Sang chu" epic of the Thai people, the epic "The origin of the world and the people" of Muong people, "khen" dances, love songs of Hmong boys and girls during festivals or "Khua ke" singing in the funeral rituals of the Hmong people, ... for generations have been supporting people to reach good values of life. These intangible cultural values have been making an important contribution to the ethnic cultural identity, preserving and conveying the cultural values of ethnic groups over generations.

However, in addition to the aforementioned positive aspects, the life-cycle beliefs of ethnic groups also have negative impacts on the people's social life. Although life-cycle beliefs are only a belief system with rituals 
related to the transitional periods of people in the family, they are costly rituals in terms of time and money, especially wedding ceremonies and funeral rituals.

In many ethnic minority residential areas, especially in the remote ones, women who give birth still have to perform too many rituals. The abstinence and anti-scientific practices have greatly affected the health of women and children. Whenever they are sick, due to the notion of lost souls, people in remote areas often do not get examined and treated based on the scientific methods but they only pray, make offerings, call the souls back and etc.

The rituals in marriage of the Thai, Muong and Hmong people are now much simpler than before. The challenge issued by the girl's family to exact wedding-presents in the form of white silver from the future groom's family, the custom of taking the buffalo to the girl's house to make offerings to marry and ancient practices such as tasting wine residues, throwing rice husks into the groom's family when they come to the bride's house to take the bride, straining the rope and closing the gate to ask for money no longer exist now. But here and there, in some ethnic minority areas, marriage with lots of costly offerings is still a burden on the lives of the people here. For example, a Me family in Yen Chau district, Son La prepared the offerings for the son's wedding as follows: 60 white silver coins called ngân khà hùa (the expense the bride's family has gone in order to raise her and bring her up); 5 to 10 silver coins called ngân khỏ khén (mother milk expense); 80 chickens from 0.6 to $1 \mathrm{~kg}$ each; 80 bamboo tubes containing pork, buffalo meat or salted beef, weighing about $0.3 \mathrm{~kg}$ each; 80 dried fish gabions, each containing 3 pieces; 5 - 10kg of salted beef and powdered grilled rice put into the jars to dry; 01 buffalo or a cow of 100kg or more, 01 pig weighing 10kg or more, 100kg of sticky rice (Cam Vi Hoa Quynh, 2009).

It also costs the girl's family a lot because they have to prepare a dowry for their daughter to bring to her husband's home. Mr. Ca Van Sich's family currently live in Na Nhai village, Muong Chum commune, Muong La district, Son La province (there are 9 children including 3 boys and 6 girls all of whom are married). The dowries he prepared for his daughters to bring to the marriage is as follows: The first daughter: 6 blankets, 6 cushions; 20 pairs of "piêu" towels and pillows; a set of cooking utensils includes: 1 basket and 1 pot to cook steamed sticky rice, a set of dishes including 10 large bowls, 10 small bowls and 10 plates. The second, third, fourth, and fifth daughter: each one got 10 blankets, 10 cushions; 1 sewing machine; 30 pairs of "piêu" towels and pillows; a new set of saucepans and pots, 10 new bowls and plates. The youngest daughter: aside from the things given to her sisters, she was also given a pregnant sow, a dog, a cat and some ducks for breeding to make a living...).

In many ethnic minority areas in the Northwest region, violations to the laws on marriage and family is still quite common (getting married without registration and getting married before reaching the legal age). In addition, the issue of gender inequality still exists. The role of ethnic women (Muong, Hmong) has not been properly recognized and evaluated.

The funeral rituals of all three ethnic groups of Thai, Muong and Hmong still contain a number of old-fashioned and outdated customs. People here have no longer left dead people in the house for a long time as before but nowadays, it is quite common to leave dead people in the house for 2 to 3 days. The funeral still contains several different rituals that require a lot of time and money. Particularly, in some remote areas, Mong people still maintain the fresh ghost and dried ghost rituals, slaughter buffaloes and cows, eat and drink in the field beside the corpse.

\subsection{The Changes in Life-cycle - Related Beliefs in the Cultural Life of Ethnic Minorities in Northwestern Vietnam}

Maintaining a lot of old-fashioned and outdated customs related to marriage and funeral rituals in the life-cycle beliefs has hindered the socio-economic development of ethnic minority people in northwestern Vietnam. In addition, the beauty of traditional culture in the life-cycle beliefs of the people here is fading away and changing. Due to the adverse effects of the market economy and the cultural exchanges among ethnic groups, the tradition of sharing and supporting each other physically and spiritually of all village members with each family when there are a happy or sad event is also gradually changing, and the people are no longer as attached to each other as before. According to the traditional custom, when a family has good news or bad news, it is the good news and the bad news of the whole extended family and the village as well. Therefore, all members of the extended family and in the village expressed their concern not only emotionally but also physically via material contribution, etc. This custom represents mutual support in the community, helping to strengthen and integrate strong community relationships. However, today, this tradition has gradually disappeared in ethnic communities.

The traditional weddings of the ancient ethnic people include a lot of folk songs bearing the ethnic cultural identity. Currently, the smooth lyrics containing lots of cultural values of ethnic groups are disappearing. In many ethnic youth's weddings today, rock and rap music is used instead of smooth folk songs, the traditional costumes of the ethnic people are also gradually being replaced by costumes resembling those of Kinh people. 
Instead of wearing traditional costumes of the people, several brides and grooms of ethnic people today prefer to wear white dresses with long layers, suits, tie and leather shoes. In the wedding, ethnic boys and girls dance together in heavy music. Beer and spirits have appeared, instead of ethnic alcohol

Besides, the organization of eating and drinking for several days in the wedding is on the rise. In some areas, people used to slaughter pigs in the past, but at present, weddings where people have to slaughter both pigs and cows and last 3 days to 4 days are no longer a rare phenomenon.

In some areas where ethnic minorities intermingle with Kinh people, they acquire randomly the life-cycle beliefs of other ethnic groups. According to traditional practices, Thai people do not have reburial rites. After the dead is buried, his/her soul is taken to reside on the family altar. On the occasions of Tet and holidays, the family will make a ceremony to worship the ancestral spirits. However, at present, in some areas where Thai people intermingle with or live near the Kinh people, it is observed that the Thai people begin to hold worshiping ceremonies for the 3th day, 9th day and 49th day of the burial event and organize a big party like the Kinh people do which leads to increasing cost and a loss of specific features in the ethnic cultural identity.

Many good and beautiful features in the customs of the people here are also gradually fading away. In the past, the Thai and Muong people had a very clear and meaningful custom of "sleeping visit". According to the custom, young women reaching adulthood go to work in the field during the day and at night, they light a lamp, drop the curtain early and stay in it. The young men who notices the girl they like before, would find a chance to visit and sleep with her in the evening. If the light in the girl's chamber is still bright, it means no one has come to "partake". The boy has to open the door himself to enter the house. When he got in, the boy would lie down next to the girl and have to let the girl turn off or turn down the light. The two people can only talk and share their thoughts without touching each other. Muong ethnic people believe that affection is not only a private affair of a couple, but also a common concern of the earth god (the land god who takes care of each family's business), the ancestors and the family. Therefore, the boy must try to open the door and approach the girl's bed to talk with her while being witnessed by the family. The act of opening the door is also a chance for the guy to demonstrate his skills and talents. "Entering the house, getting to the bed" of the favorite girl is also an opportunity for the guy to learn about the family conditions of the girl he can marry, ... After several nights learning about each other like that, the girl can decide whether or not to let him "sleep with her for real". In order to "sleep with each other for real", the two have to tell the parents and families of both sides to see if they are of suitable ages. When the "real sleep" time begins, it is also the time for the boy to come to work for the girl's family. During the day he goes to work with the girl's family. At night, he sleeps with the girl he intends to learn about. During this time, the boy cannot go home. If he wants to return, he must be allowed by the girl's family. If the girl does not like the boy, the girl will pack clothes with a package of rice, put them in a basket and tell the boy: "Just go home!", and that means the girl has just refused. Or the girl may say: "Yesterday, I had a nightmare", just like that the guy understands that he is not accepted.

Currently, the sleeping visit custom is no longer maintained, but in some local regions, it is deformed and commercialized. Many boys and girls take advantage of the sleeping visit custom to "exchange their feelings" through "bargains". Prices for each "real sleep" range from 50,000 VND to 100,000 VND. The custom of sleeping visit is a cultural feature but it is gradually being trivialized and transformed into prostitution.

The Hmong custom of "wife-kidnapping" is also gradually being transformed. The process of "wife-kidnapping" is considered a cultural characteristic of the Hmong marriage. When the Hmong boys and girls have consented to each other, the boy will find a way to kidnap the girl to make her his wife. If the couple loves each other but due to poverty, they cannot afford the bride price or because the girl's parents do not agree, then the two will discuss a plan for the boy to "kidnap" her as a wife. The girl has agreed but still pretends to cry and react. If a boy love a girl unilaterally and kidnap the person he love, the girl will find a way to escape or the boy will let her escape. At that time, the boy's family will have to bring the offerings to the girl's house to compensate for her honor. From a custom of profound humanity, it is now gradually transformed into kidnapping for sexually abuse or woman trafficking, affecting the lives of many Hmong girls who are at the age of attending school.

It can be said that the modern culture is having a strong influence on all ethnic communities in Vietnam. It contributes to improving the living standards of ethnic minorities but it also obscures and even abuses cultural values of ethnic identity.

\subsection{The Solution to Promote Cultural Values in the Life-cycle - Related Beliefs of Ethnic Minorities in the Northwest region of Vietnam}

To preserve and promote the cultural values in the life - cycle - related belief of ethnic minorities in the Northwest region and gradually reduce backward and inappropriate elements in the belief activities of the people 
here, it is necessary to synchronize the following solutions:

Firstly, to study, recognize and appreciate the cultural values of life - cycle - related beliefs, and the limitations of rituals in the practice of lifelong beliefs in the cultural life of ethnic minorities in the Northwest region now.

One of the important reasons that ethnic minorities still rely heavily on natural beliefs and maintain in their lives with many rituals and customs that are no longer consistent with the development trend of new society, ethnic minorities are not self-aware of the gradually loss of their ethnic cultural identity because of their limited awareness. Therefore, it is necessary to develop specific programs and plannings for the collection, research, evaluation and dissemination of research results on the cultural and belief values of ethnic minorities so that the people here know more about the cultural value of their people. At the same time, the policy of preserving and promoting the traditional cultural values of ethnic groups must be based on the right awareness and appreciation of the positive cultural values and the limitations and backwardness of rituals in lifecycle belief of ethnic minorities. Since then, giving propaganda for ethnic minorities so that they have a sense of preserving good traditional cultural values and voluntarily eliminating backward rituals and practices in childbirth, marriage, funerals and treatment.

Secondly, promote positive cultural values of life-cycle - related beliefs in the movement of building new rural areas and building cultural life in residential areas in the Northwest of Vietnam.

In the new rural construction movement and the movement to build cultural life in residential areas, especially building a new lifestyle in marriage, funerals, ... in the Northwest region, the attention should be paid to respect, inherite and promote good cultural values in traditional beliefs in general and the lifecycle beliefs of the ethnic minorities here in particular. Doing this firstly to ensure the spiritual needs and freedom of beliefs and religion of ethnic minorities. At the same time, when the good cultural values of their traditional beliefs are inherited, promoted in the programs of socio-economic development and cultural movements, ethnic minorities will see closeness and be active to participate in. In order to promote the good cultural values of the lifelong beliefs, the localities in the Northwest region need to be instructed so that villages and hamlets build the regulations in accordance with the law, fine customs and living conditions of each ethnic group in organizing weddings, funerals, treatment, ... Simultaneously, it is necessary to do well the propaganda and dissemination activities for ethnic minority people there so that they perform rituals in traditional beliefs and promote national cultural identity and strictly implement the provisions of the law. In particular, it is necessary to encourage the people to use traditional costumes in important ceremonies, maintain the national folk songs in religious rituals,....

Thirdly, build cultural institutions in ethnic minority areas to promote cultural values of traditional beliefs in the lives of ethnic minorities here.

Building cultural institutions means investing in building infrastructure for cultural activities, while training the contingent of cultural cadres along with promulgating regulations to putting that infrastructure into the operation that aims to create a high social community environment. Through these cultural and social institutions is to attract, gather the masses, propagate and educate to build a new cultural lifestyle, preserve and promote traditional cultural and religious values in the lives of ethnic minorities in the Northwest.

Fourthly, focus on socio-economic development and encourage expansion of cultural exchanges.

Currently, the lives of ethnic minorities in the Northwest region still face many difficulties, low levels of socio-economic development, and the livelihoods of the people are mainly based on shifting cultivation and living standard of the people is much lower than the average living standard of the whole country, education, health, information, ... conditions are poor. The culture of ethnic minorities that is despite richness, diversity and richness in identity, being self-contained, and many cultural values are being eroded. Meanwhile, many backward practices, depraved customs, superstitions in traditional beliefs in general, and in lifecycle beliefs in particular that still exist persistently, even there is the signs of resurgence stronger.

In that situation, to preserve and promote good cultural values and remove negative values in the life- cycle related beliefs of ethnic minorities in the Northwest, it is necessary to focus on investment in economic - social development, improving living standards and intellectual standards for the people. Besides, it is necessary to expand cultural exchanges, enrich the cultural values of ethnic groups, overcome the inferiority attitude in the conception of ethnic minorities. Thereby, create favorable conditions for ethnic minorities to have a deep understanding of the history and culture of their ethnic groups, appreciate, preserve and promote their good traditional cultural values in the lives of individuals, families and society.

\section{Conclusion}

Traditional Beliefs in general, beliefs of lifecycle in particular are both products and reflections on real social life. 
Like other types of religions and traditional beliefs, the beliefs of lifecycle of the ethnic minorities in the Northwest region of Vietnam is born and exists based on certain conditions of the social environment, it reflects the will and human thinking, but it is also slowly changing compared to the socio-economic basis where it is generated. Outdated, inadequate and obsolete elements that still exist in the lifecycle rituals have been revealing their countervailing values and becoming obstacles to the socio-economic development of the people here.

Besides, in the new trend of the nation and the era, the practices of life - cycle - related beliefs of ethnic groups is also facing great challenges. The risk of gradual disappearing of ethnic cultural identity is taking place in parallel with the process of restoring backward customs and practices. Therefore, paying attention to preserving and promoting traditional cultural values and simultaneously propagandizing and mobilizing ethnic minority people to gradually eliminate outdated and obsolete elements in activities of life - cycle - related beliefs must be paid attention to solve in a satisfactory manner to contribute to build an advanced Vietnamese culture imbued with national identity.

\section{References}

Binh, T. V. (chief editor). (2004). Culture of Northwestern ethnic groups, current situation and issues. National Political Publishing House of Vietnam, Hanoi.

$\mathrm{Cu}, \mathrm{H}$. T. (2005). Something about the beliefs of the Thai people in the Northwest region in Vietnam. Religious Studies Review, 4, 45-51.

Duy, N. D. (2001). Forms of religious beliefs in Vietnam. Culture and Information Publishing House, Hanoi.

Hoa, N. T. K. (2012). Beliefs of Muong people in Hoa Binh. Journal of Art and culture, 4, 12-15.

Khanh, V. N. (2004). Cultural traditions of Vietnamese ethnic minorities. Youth Publishing House, Hanoi.

Khang, N. T. (2013). Cultural characteristics and values of folk beliefs in Vietnam. Religious Studies Review, 6, 27-32.

Lan, H. T. (2016). Beliefs of ethnic minorities in mountainous areas of the North region in Vietnam. Vietnam social sciences review, 100, 107-113.

Le, N. V., Tiep, N. V., \& Dieu, N. V. (1998). Culture of ethnic minorities in Vietnam. Vietnam Education Publishing House, Hanoi.

Luong, H. (2002). Traditional festivals and folk beliefs of Vietnamese ethnic minorities (the northern provinces). Hanoi National University Publishing House, Hanoi.

Nam, L. B. (2015). Culture of ethnic groups in the northwest region in Vietnam. VietSense Travel. Retrieved from https://vietsensetravel.com/dac-trung-van-hoa-cac-dan-toc-o-tay-bac-n.html.

Nga, N. T. T. (2015). Some basic issues on ethnic areas of ethnic groups in the Northwestern. Border in Vietnam. Retrieved from http://bienphongvietnam.vn/nghien-cuu-trao-doi/thong-tin-tu-lieu/1460-ddd.html

Nhuan, D. T., Phuong, D. Q., \& Tam, P. T. (2014). Traditional cultural values of the Thai ethnics in northwest of Vietnam for developing community-based tourism. Journal of Science Ho Chi Minh city university of Education, 60, 190-199.

Quang, V. D. (2005). The spiritual culture of the Hmong in traditional and modern Vietnam. Culture and Information Publishing House, Hanoi.

Quynh, C. V. H. (2009). Beliefs of Thai people in Son La today. Master in Philosophy thesis, Ho Chi Minh National Academy of Politics, Hanoi, 70-85.

Sam, M. T. (2008). Beliefs of Hmong people in Lao Cai today. Master in Philosophy thesis, Ho Chi Minh National Academy of Politics, Hanoi.

Son, T. H. (1996). Hmong culture. Ethnic Culture Publishing House, Hanoi.

Thao, P. M. (2004). Funeral customs. Culture and Information Publishing House, Hanoi.

Thinh, N. D. (Chief editor). (2001). Cultural beliefs and beliefs in Vietnam. Social Sciences Publishing House, Hanoi.

Trong, C. (1978). Thai people in the Northwest of Vietnam. Science and Technics Publishing House, Hanoi.

Van, D. N., Son, C. T., \& Hung, L. (2016). Ethnic Minorities in Vietnam. The Gioi Publishers, Hanoi.

Vu, L. T. (1999). Human lifecycle rituals. Culture and Information Publishing House, Hanoi. 


\section{Copyrights}

Copyright for this article is retained by the author(s), with first publication rights granted to the journal.

This is an open-access article distributed under the terms and conditions of the Creative Commons Attribution license (http://creativecommons.org/licenses/by/4.0/). 